\title{
SOCIEDADE DE PROPÓSITO ESPECÍFICO COMO MECANISMO JURÍDICO DE DESENVOLVIMENTO DAS MICRO E PEQUENAS EMPRESAS
}

\author{
Rafael Seixas Santos* \\ Paulo Afonso Cavichioli Carmona**
}

SUMÁRIO: Introdução; 2 Sociedade de Propósito Específico formada por MPE como mecanismo catalisador do desenvolvimento econômico; 3 Da Potencial redução das falbas de mercado por ocasião da formação da SPE entre as MPE's; 4 Considerações finais; Referências.

RESUMO: O texto objetiva discutir sobre os efeitos do emprego da Sociedade de Propósito Específico (SPE) como mecanismo jurídico inclusivo das micro/pequenas empresas (MPE) no mercado, inclusive das contratações públicas. Como método, argumenta-se com base em conceitos e considerações amplas, à luz de descritores como a eficiência econômica e o bem-estar global, acerca dos efeitos da adoção das SPE. Os resultados são que, no plano teórico, as SPE estão ligadas ao aumento da participação das MPE no mercado, por meio da assunção de uma estrutura capaz de diluir os riscos jurídico e econômico, eis que a participação de empresas micro e pequenas nas SPE facilita a circulação de produtos, serviços, tecnologias e conhecimento. A análise crítica conclui anotando a real necessidade de um desenho jurídico-econômico que catalise o emprego do associativismo como mecanismo de desenvolvimento, pela via da promoção de estratégias inovadoras como meio de fortalecimento micro empresarial e pela clarificação das políticas públicas nesta seara.

PALAVRAS-CHAVE: Desenho Jurídico; Desenvolvimento; Microempresa; Sociedade Propósito Específico.

\section{SOCIET Y WITH SPECIFIC AIMS AS A JURIDICAL MECHANISM FOR THE DEVELOPMENT OF MICRO AND SMALL FIRMS}

ABSTRACT: The employment effects of a Society with Specific Aims (SSA) as a juridical mechanism, inclusive of Micro/Small Firms (MSF) on the market, including

\footnotetext{
Mestre em Direito e Políticas Públicas pelo Centro Universitário de Brasília (UniCEUB); Docente do Instituto de Educação Superior de Brasília (IESB), Vinculado ao Grupo de Pesquisa em Políticas Públicas do Programa de Doutorado em Direito do Centro Universitário de Brasília (UniCEUB), Brasil.

E-mail: rafaelseixas.email@gmail.com

${ }^{*}$ Doutor em Direito Urbanístico pela Pontifícia Universidade Católica de São Paulo (PUC/SP); Docente do Programa de Mestrado e Doutorado do Centro Universitário de Brasília (UniCEUB), Membro do Grupo de Pesquisa de Meio Ambiente Urbano (PUC/SP); Juiz de Direito do Tribunal de Justiça do Distrito Federal e Territórios (TJDFT), Brasil.
} 
public agreements, are discussed. Arguments are based on wide concepts and considerations through descriptors such as economic efficiency and global welfare, on the effects of SSA use. Results show that SSAa are linked to increase in the participation of MSFs on the market due to a structure which is capable of mitigating juridical and economic risks. Consequently, the participation of micro and small firms in SSAs disseminates products, services, technologies and knowledge. Critical analysis shows the true needs of a juridical and economical design that catalyzes associativeness as a development mechanism through the promotion of innovatory strategies as a means of strengthening micro-entrepreneurships and through the clarification of public policies.

KEY WORDS: Juridical design; Development; Micro-firm; Society with specific aims.

\section{SOCIEDAD DE PROPÓSITO ESPECÍFICO COMO MECANISMO JURÍDICO DE DESARROLLO DE LAS MICRO Y PEQUEÑAS EMPRESAS}

RESUMEN: El texto tiene como objetivo discutir sobre los efectos del empleo de la Sociedad de Propósito Específico (SPE) como mecanismo jurídico inclusivo de las micro/pequeñas empresas (MPE) en el mercado, inclusive de las contrataciones públicas. Como método, se argumenta con base en conceptos y consideraciones amplias, a la luz de descriptores como la eficiencia económica y el bienestar global, acerca de los efectos de la adopción de las SPE. Los resultados son que, en el plano teórico, las SPE están ligadas al aumento de la participación de las MPE en el mercado, por intermedio de la asunción de una estructura capaz de diluir los riesgos jurídico y económico, una vez que la participación de empresas micro y pequeñas en las SPE facilita la circulación de productos, servicios, tecnologías y conocimiento. El análisis crítico concluye apuntando la real necesidad de un diseño jurídico-económico que catalice el empleo de la asociación como mecanismo de desarrollo, por la ruta de la promoción de estrategias innovadoras como medio de fortalecimiento micro empresarial y por la clarificación de las políticas públicas en esta área.

PALABRAS-CLAVE: Diseño Jurídico; Desarrollo; Microempresa; Sociedad Propósito Específico. 


\section{INTRODUÇÃO}

A preocupação com o desenvolvimento econômico nacional fez com que o constituinte assentasse o tratamento favorecido para as empresas de pequeno porte fundadas sob as leis brasileiras e que tenham sua sede e administração no país como princípio orientador da Ordem Econômica Nacional.

Referido preceito, retomado em diversas outras passagens do texto constituciona $\mathrm{l}^{03}$, deve sua concretude, em grande parte, à edição do Estatuto da Micro e Pequena Empresa ${ }^{04}$, o qual veicula, como mecanismo de promoção do desenvolvimento nacional, a formação de Sociedade de Propósito Específico (SPE).

Não é em vão que se sustenta a promoção das MPE no cenário econômico, eis que se cuida de verdadeira estratégia de estímulo à competitividade em micro e macro escala, inclusive na seara das contratações públicas. Percebe-se que o microssistema jurídico das Micro e Pequenas Empresas (MPE) elucida uma proposta de atribuição de compensações àqueles que são, ao menos em tese e a priori, economicamente mais frágeis ${ }^{05}$. Deste arcabouço, a SPE emerge como instrumento de inclusão e promoção das pequenas empresas no campo de negociações, instrumento que, todavia, ainda não despontou no cenário econômico nacional com toda a amplitude de alcance que lhe deposita.

Com efeito, enquanto mecanismo de ação deste microssistema, a utilização da SPE merece análise em virtude de seu potencial de geração de produtos ou processos produtivos diversificados e, muitas vezes, inovadores, de que tanto carece o mercado brasileiro.

A proposta deste texto é, assim, empreender uma discussão sobre as condições de possibilidade da SPE despontar como mecanismo jurídico de inclusão

\footnotetext{
${ }^{03}$ BRASIL. Constituição (1988). Constituição da República Federativa do Brasil. Brasília: Senado Federal: Centro Gráfico, 1988.

${ }^{04}$ Lei Complementar $\mathrm{n}^{\circ} 123$ de 14 de dezembro de 2006. Institui o Estatuto Nacional da Microempresa e da Empresa de Pequeno Porte; altera dispositivos das Leis $\mathrm{n}^{\circ} 8.212$ e 8.213, ambas de 24 de julho de 1991, da Consolidação das Leis do Trabalho - CLT, aprovada pelo Decreto-Lei ${ }^{\circ} 5.452$, de $1^{\circ}$ de maio de 1943 , da Lei $\mathrm{n}^{\mathrm{o}} 10.189$, de 14 de fevereiro de 2001, da Lei Complementar $\mathrm{n}^{\circ} 63$, de 11 de janeiro de 1990; e revoga as Leis $\mathrm{n}^{0}$ 9.317, de 05 de dezembro de 1996, e 9.841, de 05 de outubro de 1999.

${ }^{05}$ Neste sentido já se pronunciou o STF, no Julgamento da ADI 4033-DF, cujo trecho da ementa dispõe: "[...] O fomento da micro e da pequena empresa foi elevado à condição de princípio constitucional, de modo a orientar todos os entes federados a conferir tratamento favorecido aos empreendedores que contam com menos recursos para fazer frente à concorrência [...]".
} 
das MPE no processo de desenvolvimento econômico, seu emprego nas licitações ${ }^{06}$ e, de um modo geral, na arena nacional. Por meio da invocação de conceitos e considerações amplas, formulados por diversos autores, será construída uma plataforma conceitual homogênea que elucide, à luz dos conceitos de eficiência econômica e de bem-estar global, apropriados da análise econômica do direito ${ }^{07}$, como o arcabouço institucional de formação da SPE pode induzir ao desenvolvimento econômico e aumentar o referido bem-estar.

Assim, sob o prisma daqueles elementos conceituais, é possível discutir a adoção da SPE como instrumento da política associativa das pequenas empresas para a promoção do desenvolvimento no âmbito nacional, por promover eficiência jurídica e econômica no desenho empresarial. Busca-se, assim, a instituição de um direito eficiente, conducente à eficiência como valor econômico primordial do ordenamento jurídico - eis aí o conceito de eficiência considerado no texto: a teórica capacidade de as MPE realizarem mais negócios produzidos por um razoável rearranjo estrutural.

A avaliação considera a atual crise das formas tradicionais de associação das MPE, havida diante do esgotamento do cenário político-econômico brasileiro. A adequação do direito à realidade, que deve permear o aludido cenário, deriva diretamente do assentamento político e da propensão econômica para o desenvolvimento. Considera-se que o estímulo ao desenvolvimento nacional pode emergir de uma miríade de estratégias inovadoras, que passam pelo associativismo como meio de fortalecimento empresarial, sobretudo em se tratando de MPE.

Segundo dados do último levantamento da Representatividade dos Pequenos Negócios no Brasil (2014) - SEBRAE, em um país no qual as atividades (produtivas, de serviços e comerciais) desenvolvidas pelas menores empresas respondem por aproximadamente $27 \%$ (vinte e sete por cento) do Produto Interno Bruto (PIB), é forçoso vislumbrar e investigar estratégias jurídicas de fortalecimento das MPE.

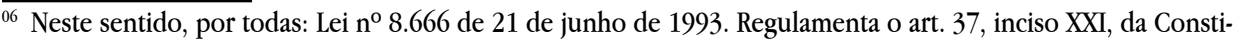
tuição Federal, institui normas para licitações e contratos da Administração Pública e dá outras providências e Lei $n^{0} 11.079$ de 30 de dezembro de 2004. Institui normas gerais para licitação e contratação de parceria público-privada no âmbito da administração pública.

${ }^{07}$ GICO JÚNIOR, Ivo. RIBEIRO, Marcia Carla. O que é análise econômica do direito: uma introdução. Belo Horizonte: Fórum, 2011.
} 
Tabela 1. Distribuição percentual do valor adicionado das Micro e Pequenas Empresas 1985 $-2001-2011^{08}$

\begin{tabular}{|lccc|}
\hline \multirow{2}{*}{ \% DO VALOR ADICIONADO DAS MPE } & \multicolumn{3}{c|}{ ANO } \\
\cline { 2 - 4 } & $\mathbf{1 9 8 5}$ & $\mathbf{2 0 0 1}$ & $\mathbf{2 0 1 1}$ \\
\hline Serviços & $5,84 \%$ & $8,30 \%$ & $10,0 \%$ \\
Comércio & $5,90 \%$ & $6,80 \%$ & $9,10 \%$ \\
Indústria & $9,30 \%$ & $8,10 \%$ & $7,80 \%$ \\
Micro e Pequenas Empresas & $21,0 \%$ & $23,2 \%$ & $27,0 \%$ \\
\hline
\end{tabular}

Fonte: Dados da pesquisa

Nesse contexto, a hipótese é da construção dos arranjos da SPE como alternativa jurídica à (retomada da) promoção do desenvolvimento econômico, a partir da amálgama a ser gerada pela comunhão de esforços empresariais e, de modo suplementar, estatais. Desponta, ainda, a SPE como um canal facilitador do incremento do bem-estar global em virtude da eficiência promovida pela vantagem individualmente obtida pelas MPE na sua participação nas rodadas de negócios.

Assim, o conceito de bem-estar desenvolvido no texto considera os efeitos ideais da alocação ótima de recursos, por meio do emprego da SPE, relacionando o conceito de produção de utilidades, em uma modelagem que considera as melhorias para MPE com base em seu correspondente acréscimo de faturamento ${ }^{09}$.

Portanto, o texto objetiva analisar o emprego das Sociedades de Propósito Específico entre as Micro e Pequenas Empresas no país à luz dos conceitos de eficiência e bem-estar, discutindo um desenho jurídico-econômico adequado à adoção do associativismo como mecanismo de desenvolvimento nacional.

\section{SOCIEDADE DE PROPÓSITO ESPECÍFICO FORMADA POR MPE COMO MECANISMO CATALISADOR DO DESENVOLVIMENTO ECONÔMICO}

A Sociedade de Propósito Específico não é inovação do Estatuto das MPE, e a sua primeira referência foi a Portaria $\mathrm{n}^{0} 107$ de 1967, do Instituto Brasileiro de Desenvolvimento Florestal - IBDF, a qual institui o chamado consórcio societário,

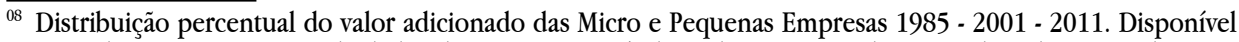
em: Sebrae e FGV, a partir de dados do IBGE. Disponível em: http://www.sebrae.com.br/Sebrae/Portal\%20Sebrae/Estudos\%20e\%20Pesquisas/Participacao\%20das\%20micro\%20e\%20pequenas\%20empresas.pdf (p. 32).

${ }^{09}$ FELDMAN, Allan M.; SERRANO, Roberto. Welfare economics and social choice theory. Springer Science \& Business Media, 2006.
} 
determinando que a conjugação empresarial visando a venda, no exterior, das mercadorias ali elencadas se fizesse mediante a criação de um ente, dotado de personalidade jurídica, abrangendo a forma da sociedade comercial, organizada por instrumento público ou particular e com seus atos constitutivos arquivados na repartição competente ${ }^{10}$.

Pode-se conceituar a SPE como a sociedade cujo objeto social é limitado a um fim específico e cuja razão de existência é unicamente o cumprimento desse propósito, findo o qual, resolve-se a sociedade.

A SPE não dispõe de um interesse empresarial propriamente produzido e não cumpre um objeto social ordinário, de modo que não se destina a desenvolver uma "vida" social, senão uma "vida" cronometrada. Trata-se de uma sociedade ancilar, de mero instrumento de ação dos seus integrantes-fundandores ou participantes. Deveras, essas sociedades são instituídas para prestar um serviço a seus controladores, para cumprir mera etapa de um projeto, ou, por vezes, para desenvolver um projeto especial. Normalmente, cumprido esse projeto, o seu destino é a liquidação. Nascem, deste modo, já marcadas para morrer ${ }^{11}$.

O instituto é resultante da celebração de um contrato de sociedade, no qual a sociedade empresária, dotada de personalidade jurídica e autonomia patrimonial, é constituída especificamente para uma ação ou projeto.

Como visto, não se trata de um ente exclusivamente nacional. No direito norte-americano, por exemplo, existe a figura da Special Purpose Company (SPC) ${ }^{12}$, equivalente à Sociedade de Propósito Específico brasileira. Também conhecida como Special Purpose Entity ou Special Purpose Vehicle ou Shell Company, a SPC surgiu como mecanismo de securitização das hipotecas garantidas pelo governo.

Atualmente, em paralelo com a SPE, a SPC funciona como um veículo estabelecido para conduzir um propósito especifíco ou limitado, de modo que:

Firms have used SPEs [Special Purpose Entities] to do a number of things. Some of the more common things SPEs are used for include selling or transferring assets do the SPE, all sorts of leasing activities, borrowing money, issuing one type of equity to the SPE that is converted into another type of security, creating research and development vehicles, and as heading devices $[\ldots]^{13}$.

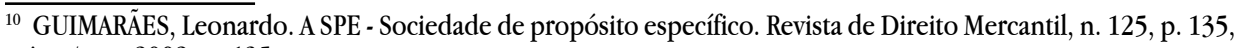
jan./mar. 2002. p. 135.

${ }^{11}$ BORBA, José Edwaldo Tavares. Direito Societário. 9. ed. Rio de Janeiro: Renovar, 2004, p. 518.

12 ESTADOS UNIDOS DA AMÉRICA. The Small Business Jobs Act of 2010 (H.R. 5297). PUBLIC LAW 111-240SEPT. 27, 2010. Disponível em: <http://www.gpo.gov/fdsys/pkg/PLAW-111publ240/pdf/PLAW-111publ240. pdf > . Acesso em: 13 jan. 2016.

${ }^{13}$ KETZ, J. Edward. Hidden Financial Risk: understanding off-balance sheet accounting. Hoboken: John Wiley \& Sons, Inc., 2003. p. 126-127.
} 
De seu turno, o Estatuto das Micro e Pequenas empresas tratou de disciplinar a Sociedade de Propósito Específico como materialização do associativismo, instrumento jurídico voltado para a inclusão das menores empresas no mercado de aquisições públicas e nas rodadas de negociação dos mercados doméstico e internacional ${ }^{14}$.

O fato de as MPE optantes pelo Simples Nacional estarem autorizadas a instituir SPE com o fito de realizar negócios de compra e venda de bens confere aplicação prática aos preceitos constitucionais favorecedores das menores empresas e do desenvolvimento nacional ${ }^{15}$.

Daí se vislumbra o condão das SPE para a inserção das pequenas empresas no mercado. Este entendimento é esposado pelo Superior Tribunal de Justiça que, em trecho da Ementa do Julgamento do Recurso Especial $n^{0} 1.236 .488$, assentou que todos os entes federados devem dispensar: "tratamento favorecido aos empreendedores que contam com menos recursos para fazer frente à concorrência, em consonância com as diretrizes [...] da Constituição Federal".

A SPE, constituída como sociedade limitada, registrada na Junta Comercial, dispõe de personalidade jurídica que lhe habilita a obter financiamentos, pleitear registros de patentes, emitir notas fiscais, firmar contratos em nome próprio; enfim, a exercer aptidões que lhe conferem "maior flexibilidade e vantagem competitiva, em campos de atuação diversos até mesmo daqueles atuados pelas MPE participadas"16 que lhe deram forma.

A potencialidade da SPE, quando de sua participação no mercado ou nas licitações e contratações públicas (fértil campo para o desenvolvimento das MPE) é desdobramento claro do seu albergue no permissivo do chamado "bloco das aquisições públicas" ${ }^{17}$ do Estatuto.

Portanto, a aliança obtida da formação da sociedade específica constitui

${ }_{14}$ MEDAUAR, Odete. Direito Administrativo Moderno. 19. ed. rev. e atual. São Paulo: Revista dos Tribunais, 2015.

15 MOTTA, Carlos Pinto Coelho; BICALHO, Alécia Paolucci Nogueira; CARVALHO, Lucila de Oliveira. As novas regras para licitações e contratações públicas. Fórum de Contratação e Gestão Pública - FCGP. Belo Horizonte, ano 10 , n. 110, p. 7-25, fev. 2011.

${ }^{16}$ FERRAZ, Luciano. Principais apontamentos acerca das sociedades de economia mista. Separata da Revista do Tribunal de Contas de Portugal, n. 26, jul./dez., 1996. p. 3.

${ }^{17}$ CARVAlHo FILHO, José dos Santos. Manual de Direito Administrativo. 27. ed. Rio de Janeiro: Lumen Juris, 2014. 
importante instrumento de retorno financeiro aos instituidores e investidores, estabelecendo $^{18}$ "um ciclo virtuoso de desenvolvimento" derivado, inclusive, da participação minoritária do Poder Público nas decisões da sociedade.

Trata-se de verdadeiro mecanismo político-jurídico de estímulo positivo por parte do Estado, com o notório fim de formatar um ordenamento que seja capaz de assegurar "segurança jurídica", "lucratividade" e, nos melhores casos, "inovação" aos negócios privados. Eis que:

A expressão 'estímulos positivos' ao exercício da atividade econômica privada é bem mais ampla que a de 'fomento', nela abrangida. Enquanto o fomento é um incentivo ao desempenho de determinada função de interesse do agente fomentador, o estímulo positivo envolve a criação de um cenário favorável aos investimentos ${ }^{19}$.

Deste modo, o albergue conferido pelo Estatuto das MPE é materializado por meio das licitações exclusivas para as $\mathrm{MPE}^{20}$ e da formação das SPE como elemento integrador e fortalecedor das menores empresas. Tudo em virtude da vultosa participação das empresas menores na produção nacional.

De se notar que o emprego da SPE, enquanto instrumento de associação, objetiva, via geral, o desenvolvimento econômico de negócios específicos em variados cenários. $\mathrm{Na}$ realidade jurídica estadunidense, por exemplo, os patrocinadores constituem a Sociedade com o fim de implantar e gerir determinado empreendimento, geralmente estruturado sob a forma de Project Finance (como fundos mútuos para financiar a expansão das pequenas empresas já existentes e incentivar a formação de novas pequenas empresas) a funcionar como mecanismo de fomento privado ao desenvolvimento econômico.

O desenvolvimento econômico brasileiro possui força normativa de objetivo da República a ser atingido pela ordem econômica, em cotejo com a promoção das garantias sociais. Em que pesem as variadas definições de desenvolvimento, registrese que o fenômeno se deslinda "como processo de modificação de ordem qualitativa

\footnotetext{
${ }^{18}$ Ferraz, Luciano; NEVES, Rubia Carneiro. Parcerias na Lei de Inovação Tecnológica: O caso das Sociedades de Propósito Específico (SPE). Revista de Informação Legislativa, Ano 51, n. 203 jul./set. 2014. p. 5.

19 SOUTO, Marcos Juruena Villela. Estímulos Positivos. In: CARDOZO, José Eduardo Martins et al. (Coord.). Direito Administrativo Econômico. São Paulo: Atlas, 2011. p. 184.

${ }^{20}$ PEREIRA JUNIOR, Jessé Torres; DOTTI, Marinês Restelato. As licitações exclusivas para microempresas e empresas de pequeno porte: regra e exceções. Fórum de Contratação e Gestão Pública - FCGP. Belo Horizonte, ano 11, n. 123 , p. 9-18, mar. 2012.
} 
e quantitativa da estrutura econômica e da sociedade"21.

No entanto, em outra via, os países emergentes apresentam falhas em suas estruturas econômicas e sociais, de modo que a rentabilidade dos investimentos não é suficientemente atrativa para o setor privado ${ }^{22}$. É necessário que ocorram aportes legais, políticos, institucionais ou financeiros por parte do Estado com o notório fito de suprir lacunas de fomento e promoção dos agentes produtivos, em especial das MPE.

O modelo brasileiro, em que o Estado apresenta um envolvimento parcial no fomento das SPE, restringindo-se a tecer um cenário normativo-legal sem, contudo, praticar uma adoção sistematizada da Sociedade em suas contratações, incapacita o Estado, as SPE e as MPE a lidarem com diferentes arranjos institucionais de organização jurídico-econômica dos países em processo de desenvolvimento ${ }^{23}$. Eis a crise:

A ideia de crise naturalmente conduz a uma visão desconstrutivista, associada ao desgaste, à perplexidade diante do esgotamento de um cenário estabelecido. De fato, o protagonismo do sujeito privado na órbita do financiamento e da prestação direta do serviço público passou a requerer a adequação do direito à realidade circundante. Todavia, a experiência demonstrou que essa adequação não se completa exclusivamente com a atividade formal no âmbito legislativo, mas especialmente por intermédio da atividade administrativa concreta ${ }^{24}$.

Ou a MPE, por meio de sua capacidade produtiva, de investimento e de inovação tecnológica ${ }^{25}$, se apresenta suficientemente atrativa a captar investimentos internos e estrangeiros, para que se habilite a compor uma SPE que lhe fortaleça a capacidade de investimento, de produção, de inovação, de contratação, de expansão, etc.; ou, frustrada tal alternativa, espera pelos estímulos positivos de fomento emergentes do planejamento indicativo estatal que lhe permitam incrementos de

\footnotetext{
${ }^{21}$ NUSDEO, Fábio. Curso de economia: introdução ao direito econômico. 5. ed. São Paulo: Revista dos Tribunais, 2015. p. 48.

${ }^{22}$ MORETTINI, Felipe Tadeu Ribeiro; GONÇALVES, Oksandro Osdival. Análise econômica do controle judicial dos contratos de concessão e sua importância para o desenvolvimento. Revista de Informação Legislativa, Ano 51, n. 203 jul./set. 2014. p. 7.

${ }^{23}$ SCHAPIRO, Mario G. Repensando a relação entre Estado, direito e desenvolvimento: a nova economia global e a relevância de um desenho jurídico-institucional adequado. Revista Direito GV, São Paulo, v. 6, n. 1, p. 213252, jan./jun., 2011.

${ }^{24}$ OLIVEIRA, Fernão Justen de. Novos Postulados para a Administração Pública. In: TALAMI, Eduardo; JUSTEN, Mônica Spezia (Coord.). Parcerias Públicos-Privadas: um enfoque multidisciplinar. São Paulo: RT, 2005, p. 6768.

${ }^{25}$ BRASIL. Lei $\mathrm{n}^{\mathrm{0}} 10.973$ de 02 de dezembro de 2004 . Dispõe sobre incentivos à inovação e à pesquisa científica e tecnológica no ambiente produtivo e dá outras providências.
} 
faturamento e de progresso.

\section{DA POTENCIAL REDUÇÃO DAS FALHAS DE MERCADO POR OCASIÃO DA FORMAÇÃO DA SPE ENTRE AS MPE'S}

As SPE estão ligadas diretamente ao aumento da participação das MPE no mercado, por meio da assunção de uma estrutura capaz de diluir o risco jurídico e econômico. O sucesso de uma SPE depende de sua capacidade de atrair investimentos (aportes financeiros, tecnológicos, patrimoniais, etc.) dos agentes privados, a saber, as MPE que a integrarão ${ }^{26}$.

A Sociedade, cujo propósito é específico, é a materialização de um mecanismo jurídico que estimula, a priori, a formatação de um arranjo que seja capaz de assegurar lucratividade, pressupondo-se harmonia e previsibilidade jurídica aos negócios nesse diapasão celebrados ${ }^{27}$.

A participação das menores empresas nas sociedades finalísticas objetiva facilitar a circulação de produtos, serviços, tecnologias e know bow, entre empreendimentos de natureza constitutiva similar. Neste sentido, inclusive, já se pronunciou o Supremo Tribunal Federal, no Julgamento da Ação Direta de Inconstitucionalidade $n^{0} 4033$, cujo trecho da ementa dispõe:

[...] O fomento da micro e da pequena empresa foi elevado à condição de princípio constitucional, de modo a orientar todos os entes federados a conferir tratamento favorecido aos empreendedores que contam com menos recursos para fazer frente à concorrência $[\ldots]$.

Por meio da associação é possível propiciar um aumento do nível das atividades das MPE, especialmente no campo das aquisições públicas - sob o cenário presuntivo de estímulos estatais positivos.

Os efeitos positivos do associativismo se sedimentam no mercado interno de modo a expandir o patrimônio nacional, pela via das políticas públicas integradoras e fomentadoras do desenvolvimento cultural e socioeconômico, o bem-estar da

${ }^{26}$ SANTANA, Jair Eduardo; GUIMARÃES, Edgar. Visão geral do Estatuto das Microempresas e seu impacto nas licitações. Fórum de Contratação e Gestão Pública - FCGP. Belo Horizonte, ano 8, n. 94, out. 2009. Disponível em: <http://bid.editoraforum.com.br/bid/PDI0006.aspx?pdiCntd=62987> . Acesso em: 04 jun. 2016.

${ }^{27}$ TOLEDO, Margherita Coelho. A SOCIEDADE DE PROPÓSITO ESPECÍFICO NO ÂMBITO DO DIREITO EMPRESARIAL BRASILEIRO - Dissertação de Mestrado - Direito Empresarial - FACULDADE DE DIREITO MILTON CAMPOS, Nova Lima, 2009. Disponível em: < http://www.mcampos.br/posgraduacao/mestrado/dissertacoes/2011/ margheritacoelhotoledosociedadepropositoespecificoambitodireitoempresarialbrasileiro.pdf $>$. Acesso em: 13 jan. 2016. 
população e o progresso tecnológico e, nos termos do art. 219 da Constituição Federal, "será incentivado de modo a viabilizar o desenvolvimento cultural e socioeconômico, o bem-estar da população e a autonomia tecnológica do País, nos termos de lei federal".

De fato, é presumível, jurídica e economicamente, que a participação de pequenas empresas no mercado das licitações pode ser um neutralizador das externalidades negativas dos monopólios e oligopólios e, sob essa perspectiva, "a tutela da pequena empresa reverbera na tutela de interesses coletivos e difusos" ${ }^{\text {" }}$.

$O$ processo de incremento do bem-estar geral depende da forma como se conduz e se estimula a participação das MPE no cenário econômico pelo emprego da SPE. Fato é que o desenvolvimento não se produz "espontaneamente":

[...] não existe a história (o passado e instituições que restringem o presente) nem geografia (a base territorial, demográfica e distâncias), o que é, exatamente, a negação da lição de Adam Smith. Ele criou duas metáforas no seu primeiro livro, 'Teoria dos Sentimentos Morais' (1759): o 'espectador imparcial' e a 'mão invisível'. A segunda ele fez clássica no livro seguinte, 'Uma Investigação sobre a Natureza e Causas da Riqueza das Nações' (1776). Resumidamente, o 'espectador imparcial' é a nossa própria razão introspectiva, que julga nosso comportamento com paixão controlada, faz um juízo moral de nossas ações e é inclinado à simpatia e ao altruísmo. A 'mão invisível' é um mecanismo de coordenação pelo qual nossas ações egoístas acabam gerando um aumento do bem-estar geral $^{29}$.

O consumo do Estado, as aquisições estatais, havidos pelas licitações e contratações públicas, pode agir como estimulante ao incremento de produção das MPE - e é justamente este o enfoque da Lei Complementar $n^{0} 123 / 06$ que vai além, ao estatuir a SPE como encaixe exato das menores empresas nesse diapasão.

Do microssistema jurídico das MPE verifica-se a propensão para, uma vez estabelecida a SPE, a formação de redes e centrais de negócios entre as próprias empresas e entre elas e profissionais liberais, a alavancar o desenvolvimento econômico.

O desenvolvimento econômico, que funciona como mecanismo de satisfação das necessidades materiais e espirituais dos indivíduos, deve ser perseguido pela

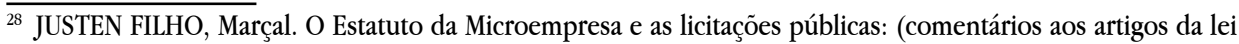
complementar $n^{0} 123$ atinentes a licitações públicas). São Paulo: Dialética, 2007, p. 20.

${ }^{29}$ DELFIM NETTO, Antônio. "Economia política". São Paulo: Folha de S. Paulo, 13 de out. de 1999. p. 2.
} 
ordem econômica nacional em ação conjunta com a promoção das garantias sociais ${ }^{30}$.

$O$ processo de desenvolvimento deve ser caracterizado pela elucidação de um conhecimento e de práticas sociais capazes de gerar uma maior inclusão possível, o que se convenciona chamar "democracia econômica"31.

Tal democracia deve ser formada, inclusive, por arranjos institucionais entre as empresas menores que, em conjunção de esforços ao redor de um propósito específico (SPE), desenvolvam atividades e produtos cujos processos produtivos e resultados sejam menos voláteis às ingerências da regulação Estatal (que sofre pressões políticas) e/ou às ondas concorrenciais das grandes empresas (muitas vezes por mecanismos de truste ou em monopólio, ainda não identificados pelas autoridades competentes).

Entretanto, por outro ângulo, como já se registrou, é possível verificar a existência de falhas nas estruturas econômicas e sociais de países emergentes, especialmente do Brasil. Tais falhas ocorrem em setores que, ao revés, deveriam ser priorizados, como de infraestrutura, de investimento em desenvolvimento e pesquisa, de funcionamento das instituições em geral.

Em razão deste cenário, a confiabilidade dos investimentos nacionais não é suficientemente atrativa, o que demanda os outrora mencionados aportes legais, políticos, institucionais ou financeiros por parte do Estado, denotando uma ainda maior ingerência estatal no funcionamento do mercado.

Para atrair os investimentos necessários, é preciso um ambiente favorável, com a menor parcela de risco possível. A formalização da SPE depende da conjugação de esforços das pequenas empresas participantes e do afastamento ótimo das ingerências do aparelho estatal (o posicionamento do Estado como agente fomentador e regulador de situações gerais e não excessivamente interveniente). Destes fatores (esforços empresariais e afastamento estatal) decorrem reduções dos custos de transaçãa ${ }^{32}$ - determinantes para as decisões jurídicas e econômicas dos agentes envolvidos.

Ocorre que os custos de transação, no Brasil, muitas vezes superam a lucratividade da atividade da sociedade, em razão da dificuldade de se interpretar e executar as vontades estatais, máxime no ambiente de imprevisibilidade econômica

\footnotetext{
$\overline{30}$ VIEIRA, Oscar Vilhena; DIMOULIS, Dimitri. Constituição e desenvolvimento. In: LIMA, Maria Lúcia L. M. Pádua (Coord.). Agenda contemporânea: direito e economia: 30 anos de Brasil. São Paulo: Saraiva, 2012. (Série GVLaw, t. 1). p. 3 .

${ }^{31}$ SALOMÃO FILHO, Calixto. Regulação e Desenvolvimento. In: SALOMÃO FILHO, Calixto (Coord.). Regulação e Desenvolvimento. São Paulo: Malheiros, 2002. p. 32-33.

${ }^{32}$ COASE, Ronald. The problem of social cost. Journal of Law and Economics, Chicago, v. 3, p. 1-44, out. 1961.
} 
e política do país.

Assim, o rearranjo das MPE com o fito de integrar uma SPE somente ocorrerá de modo pujante no mercado doméstico quando o incremento de produção, gerado pela nova formatação "empresarial", superar os custos incorridos para a sua implementação - os custos de transação.

Um dos motivos que ensejam a elevação dos custos de transação é fato de o paradigma desenvolvimentista da democracia nacional ainda se encontrar demasiadamente arraigado à ideia de que o direito deve prestar-se a garantir os interesses meramente societários, em organizações com univocidade de agir.

Em que pese a possibilidade de indução estatal nas relações privadas, não se pode autorizar ou tolerar um caráter excessivamente intervencionista. Nem se pode cogitar um Estado demasiado presente, avesso à atuação plena e livre dos administrados no domínio econômico e no domínio social ${ }^{33}$.

A gestão do Estado no domínio econômico não pode ensejar o esvaziamento dos compromissos socioeconômicos apregoados pelo Estatuto e ansiados pelas MPE. Anote-se, deveras, o contrário, eis que se deve percorrer o caminho de uma "inevitável rearticulação entre direito e política, trazendo para a alçada do direito temas que o liberalismo havia deslocado ora para o campo da política, ora para o campo da liberdade individual" ${ }^{34}$.

As peculiaridades das situações internas que demandam de normas ou atividades estatais são inúmeras, dificultando a formulação de um "modelo de sujeição" ${ }^{\text {. }}$. Isto se dá, em larga medida, em virtude de os componentes deste vínculo de sujeição dos agentes econômicos (em especial as SPE) serem definidos por normas internas derivadas de políticas públicas voláteis.

Destarte, a nãoadoção daSPEentre MPEcomocatalisadordodesenvolvimento econômico nacional é produto da barafunda institucional, sobretudo do campo econômico. Este problema de organização e disposição econômica (e jurídica) está relacionado à dificuldade de mensurar os custos envolvidos na transação associativa, especialmente quanto à escassez prática ou à baixa eficiência dos mecanismos de adaptação das MPE aos eventos jurídico-econômicos antecipáveis ${ }^{36}$.

\footnotetext{
33 FRANÇA, Vladimir da Rocha. Princípio da legalidade administrativa e competência regulatória no regime jurídico-administrativo brasileiro. Revista de Informação Legislativa. Ano 51, n. 202 abr./jun. 2014.

34 SCHAPIRO, Mario G. Discricionariedade desenvolvimentista e controles democráticos: uma tipologia dos desajustes. Revista Direito GV, v. 12, n. 2, p. 311-344, mai./ago., 2016. p. 317.

35 BARBOSA, Igor Luiz Ebihara. O regulamento autônomo e seu papel na organização da Administração Pública Federal. Revista de Informação Legislativa. Ano 51, n. 202 abr./jun. 2014. p. 223-248.

36 WILLIAMSON, Oliver. The Economic Institutions of Capitalism. New York: The Free Press, 1985.
} 


\section{CONSIDERAÇÕES FINAIS}

A realidade jurídica das Micro e Pequenas Empresas (MPE), como a de outras esferas sociais, é ancorada em uma proposta de atribuição de compensações aos mais vulneráveis economicamente, visto que é este o modo como ainda se encara as menores empresas no país, notadamente pela via das normas jurídicas específicas.

Falhas nas estruturas econômicas e sociais tornam a confiabilidade e a rentabilidade dos investimentos pouco atrativa para o setor privado, a demandar aportes (especialmente financeiros) por parte do Estado a fim de suprir as lacunas de fomento e promoção das MPE.

Referidas falhas resultaram na crise das formas tradicionais de associação das MPE, e parecem emergir do cenário político-econômico brasileiro.

Nesse bojo, a Sociedade de Propósito Específico, formada pelas MPE, pode se comportar como instrumento de inclusão e promoção, mas cuja utilização e emprego ainda não se estabilizaram.

$O$ arcabouço institucional de formação da SPE pode induzir ao desenvolvimento econômico, em virtude da promoção ao surgimento de uma miríade de estratégias inovadoras, que contam com o associativismo como meio de fortalecimento microempresarial.

O próprio Estatuto das Micro e Pequenas empresas disciplina a Sociedade de Propósito Específico como materialização do associativismo, instrumento jurídico inclusivo e que conduz as menores empresas à participação nas licitações e a comparecer aos centros de negociação dos mercados doméstico e internacional.

Deve-se vislumbrar que o Estado, tendo em vista a necessidade de inclusão mercadológica das MPE e tendo em mãos a SPE como instrumento, pode formatar um ordenamento que seja capaz de assegurar "segurança jurídica", "lucratividade" e, nos melhores casos, "inovação" aos negócios privados.

Referida inclusão mercadológica pode apresentar resultados positivos em uma tendência ao equilíbrio de mercado, quando as MPE proporcionarão um incremento de bem-estar (ainda que por absorção da fatia de mercado dominado pelas grandes monopolistas e oligopolistas), gerando um cenário eficiente, eis que consegue, em tese, obter maiores resultados com um razoável rearranjo.

Este ciclo virtuoso de desenvolvimento deriva do aumento da produtividade e da participação das MPE nas contratações, especialmente públicas, e da suavização 
da participação do Poder Público nas decisões da sociedade. O dito "bloco das aquisições públicas", como mecanismo propulsor da capacidade das MPE, por exemplo, já está materializado em larga escala na legislação nacional, que conta com a formação das SPE como elemento integrador e fortalecedor das menores empresas.

De se notar, portanto, que a participação de pequenas empresas no mercado tem o condão de tutelar interesses coletivos e difusos (direito do consumidor, a livre concorrência e liberdade de iniciativa) por meio de sua capacidade de neutralizar as externalidades negativas provenientes dos monopólios e oligopólios - que ofendem o direito do consumidor, a livre concorrência, etc.

Mas, ocorre que, no Brasil, os custos de transação podem superar a atratividade da formação da SPE, sobretudo entre as MPE, dada a dificuldade de interpretar e prever as vontades estatais. Tal fato se deve, em alto grau, à confusa agenda que atualmente se desenha.

Por isso, a não adoção da Sociedade resulta da barafunda institucional, cujas âncoras repousam na dificuldade de mensurar os custos envolvidos na transação associativa.

Com isso, por meio de conceitos da análise econômica do direito, o presente texto pôde constatar que, uma vez alcançado o afastamento ótimo das ingerências do aparelho estatal, os efeitos positivos do associativismo expandem o patrimônio nacional. Tal expansão demanda, todavia, políticas públicas de promoção do desenvolvimento cultural e socioeconômico, de aperfeiçoamento do bem-estar da população e do progresso tecnológico, a criar um ambiente favorável, com a menor parcela de risco possível, ou seja, com baixos custos de transação.

\section{REFERÊNCIAS}

BARBOSA, Igor Luiz Ebihara. O regulamento autônomo e seu papel na organização da Administração Pública Federal. Revista de Informação Legislativa. Ano 51, n. 202 abr./jun. 2014. p. 223-248.

BORBA, José Edwaldo Tavares. Direito Societário. $9^{\mathrm{a}}$ ed. Rio de Janeiro: Renovar, 2004 . 
BRASIL. Constituição (1988). Constituição da República Federativa do Brasil. Brasília: Senado Federal, Centro Gráfico, 1988.

BRASIL. Lei $\mathrm{n}^{\circ} \mathbf{8 . 6 6 6}$ de 21 de junho de 1993. Regulamenta o art. 37, inciso XXI, da Constituição Federal, institui normas para licitações e contratos da Administração Pública e dá outras providências.

BRASIL. Lei $\mathrm{n}^{\mathbf{0}} \mathbf{1 0 . 9 7 3}$ de 02 de dezembro de 2004. Dispõe sobre incentivos à inovação e à pesquisa científica e tecnológica no ambiente produtivo e dá outras providências.

BRASIL. Lei $\mathrm{n}^{\mathbf{0}} \mathbf{1 1 . 0 7 9}$ de 30 de dezembro de 2004. Institui normas gerais para licitação e contratação de parceria público-privada no âmbito da administração pública.

BRASIL. Lei Complementar $\mathrm{n}^{\circ} 123$ de 14 de dezembro de 2006. Institui o Estatuto Nacional da Microempresa e da Empresa de Pequeno Porte; altera dispositivos das Leis $n^{0} 8.212$ e 8.213, ambas de 24 de julho de 1991, da Consolidação das Leis do Trabalho - CLT, aprovada pelo Decreto-Lei $\mathrm{n}^{0} 5.452$, de $1^{\circ}$ de maio de 1943 , da Lei $\mathrm{n}^{\mathrm{o}} 10.189$, de 14 de fevereiro de 2001, da Lei Complementar $\mathrm{n}^{\circ} 63$, de 11 de janeiro de 1990; e revoga as Leis $\mathrm{n}^{0} 9.317$, de 05 de dezembro de 1996, e 9.841, de 05 de outubro de 1999.

BRASIL. Supremo Tribunal Federal. ADI 4033/DF, Relator(a): Min. JOAQUIM BARBOSA, Tribunal Pleno, julgado em 15/09/2010, DJe-024 DIVULG 04-02-2011 PUBLIC 07-02-2011 EMENT VOL-02458-01 PP-00001 RTJ VOL-00219- PP-00195 RSJADV mar., 2011, p. 28-37.

BRASIL. Superior Tribunal de Justiça. REsp 1236488/RS, Rel. Ministro HUMBERTO MARTINS, SEGUNDA TURMA, julgado em 26/04/2011, DJe 03/05/2011.

CARVALHO FILHO, José dos Santos. Manual de Direito Administrativo. 27. ed. Rio de Janeiro: Lumen Juris, 2014.

COASE, Ronald. The problem of social cost. Journal of Law and Economics, Chicago, v. 3, p. 1-44, out. 1961. 
DELFIM NETTO, Antônio. "Economia política". Folha de S. Paulo, São Paulo, 13 de outubro de 1999.

ESTADOS UNIDOS DA AMÉRICA. The Small Business Jobs Act of 2010 (H.R. 5297). PUBLIC LAW 111-240-SEPT. 27, 2010. Disponível em: http://www.gpo.gov/ fdsys/pkg/PLAW-111publ240/pdf/PLAW-111publ240.pdf Acesso em: 13 jan. 2016.

FELDMAN, Allan M.; SERRANO, Roberto. Welfare economics and social choice theory. [s.l.]: Springer Science \& Business Media, 2006.

FERRAZ, Luciano. Principais apontamentos acerca das sociedades de economia mista. Separata da Revista do Tribunal de Contas de Portugal, n. 26, jul./dez., 1996.

FERRAZ, Luciano; NEVES, Rubia Carneiro. Parcerias na Lei de Inovação Tecnológica: O caso das Sociedades de Propósito Específico (SPE). Revista de Informação Legislativa, ano 51, n. 203, jul./set. 2014.

FRANÇA, Vladimir da Rocha. Princípio da legalidade administrativa e competência regulatória no regime jurídico-administrativo brasileiro. Revista de Informação Legislativa, ano 51, n. 202, abr.jun. 2014.

GICO JÚNIOR, Ivo; RIBEIRO, Marcia Carla. O que é análise econômica do direito: uma introdução. Belo Horizonte: Fórum, 2011.

GUIMARÃES, Leonardo. A SPE - Sociedade de propósito específico. Revista de Direito Mercantil, n. 125, p. 135, jan./mar. 2002.

JUSTEN FILHO, Marçal. O Estatuto da Microempresa e as licitações públicas: (comentários aos artigos da lei complementar $\mathrm{n}^{\mathrm{0}} 123$ atinentes a licitações públicas). São Paulo: Dialética, 2007, p. 20.

KETZ, J. Edward. Hidden Financial Risk: understanding off-balance sheet accounting. Hoboken: John Wiley \& Sons, Inc., 2003. p. 126-127.

MEDAUAR, Odete. Direito Administrativo Moderno. 19. ed. rev. e atual. São Paulo: Revista dos Tribunais, 2015. 
MORETTINI, Felipe Tadeu Ribeiro; GONÇALVES, Oksandro Osdival. Análise econômica do controle judicial dos contratos de concessão e sua importância para o desenvolvimento. Revista de Informação Legislativa, ano 51, n. 203, jul./set. 2014.

MOTTA, Carlos Pinto Coelho; BICALHO, Alécia Paolucci Nogueira; CARVALHO, Lucila de Oliveira. As novas regras para licitações e contratações públicas. In: FÓRUM DE CONTRATAÇÃO E GESTÃO PÚBLICA - FCGP, Belo Horizonte, ano 10, n. 110, p. 7-25, fev. 2011.

NUSDEO, Fábio. Curso de economia: introdução ao direito econômico. 5. ed. São Paulo: Revista dos Tribunais, 2015.

OLIVEIRA, Fernão Justen de. Novos Postulados para a Administração Pública. In: TALAMI, Eduardo; JUSTEN, Mônica Spezia (Coord.). Parcerias Públicos-Privadas: um enfoque multidisciplinar. São Paulo: RT, 2005, p. 67-68.

PEREIRA JUNIOR, Jessé Torres; DOTTI, Marinês Restelato. As licitações exclusivas para microempresas e empresas de pequeno porte: regra e exceções. In: FÓRUM DE CONTRATAÇÃO E GESTÃO PÚBLICA - FCGP, Belo Horizonte, ano 11, n. 123, p. 9-18, mar. 2012.

SALOMÃO FILHO, Calixto. Regulação e Desenvolvimento. In: SALOMÃO FILHO, Calixto (Coord.). Regulação e Desenvolvimento. São Paulo: Malheiros, 2002, p. $32-33$.

SANTANA, Jair Eduardo; GUIMARÃES, Edgar. Visão geral do Estatuto das Microempresas e seu impacto nas licitações. In: FÓRUM DE CONTRATAÇÃO E GESTÃO PÚBLICA - FCGP, Belo Horizonte, ano 8, n. 94, out. 2009. Disponível em: < http:// bid.editoraforum.com.br/bid/PDI0006.aspx?pdiCntd=62987> . Acesso em: 04 jun. 2016.

SCHAPIRO, Mario G. Discricionariedade desenvolvimentista e controles democráticos: uma tipologia dos desajustes. Revista Direito GV, v. 12, n. 2, p. 311-344, maio/ ago. 2016.

SCHAPIRO, Mario G. Repensando a relação entre Estado, direito e desenvolvimento: a nova economia global e a relevância de um desenho jurídico-institucional adequado. Revista Direito GV, São Paulo, v. 6, n. 1, p. 213-252, jan./jun. 2011.

SEBRAE. Serviço Brasileiro de Apoio às Micro e Pequenas Empresas. Representa- 
tividade dos Pequenos Negócios no Brasil (2014) - SEBRAE. Disponível em: <http://www.sebrae.com.br/Sebrae/Portal\%20Sebrae/Estudos\%20e\%20Pesquisas/ Participacao\%20das\%20micro\%20e\%20pequenas\%20empresas.pdf $>$. Acesso em: 22 jun. 2016.

SEBRAE. Serviço Brasileiro de Apoio às Micro e Pequenas Empresas. Aspectos Gerais da Lei Complementar $n^{0}$ 128/08, que altera a Lei Geral das Micro e Pequenas Empresas. Sebrae Nacional Unidade de Políticas Públicas. Brasília, Nota Técnica 01/2009. Acesso em: 13 jan. 2016.

SOUTO, Marcos Juruena Villela. Estímulos Positivos. In: CARDOZO, José Eduardo Martins et al. (Coord.). Direito Administrativo Econômico. São Paulo: Atlas, 2011.

TOLEDO, Margherita Coelho. A sociedade de propósito específico no âmbito do direito empresarial brasileiro. 2009. Dissertação (Mestrado - Direito Empresarial) - Faculdade De Direito Milton Campos, Nova Lima, 2009. Disponível em: < http:// www.mcampos.br/posgraduacao/mestrado/dissertacoes/2011/margheritacoelhotoledosociedadepropositoespecificoambitodireitoempresarialbrasileiro.pdf $>$. Acesso em: 13 jan. 2015.

VIEIRA, Oscar Vilhena; DIMOULIS, Dimitri. Constituição e desenvolvimento. In: LIMA, Maria Lúcia L. M. Pádua (Coord.). Agenda contemporânea: direito e economia: 30 anos de Brasil. São Paulo: Saraiva, 2012. (Série GVLaw, t. 1).

WILLIAMSON, Oliver. The Economic Institutions of Capitalism. New York: The Free Press, 1985.

Recebido em: 10 de outubro de 2016. Aceito em: 21 de dezembro de 2016 